\title{
Reorganization of the integrin $\alpha 2$ subunit controls cell adhesion and cancer cell invasion in prostate cancer
}

\author{
SEVERINE VAN SLAMBROUCK*, AARON R. JENKINS, ANNTHERESE E. ROMERO and WIM F.A. STEELANT* \\ Laboratory of Biochemical and Biomedical Research, Department of Chemistry, \\ New Mexico Institute of Mining and Technology, Socorro, NM 87801, USA
}

Received January 21, 2009; Accepted March 23, 2009

DOI: 10.3892/ijo_00000302

\begin{abstract}
The mechanisms of invasion and metastasis are poorly understood. Our previous studies demonstrated that cancer cell invasion may result from reorganization of membrane molecules, thereby initiating signaling pathways. To increase our understanding on how cancer cells govern metastases we studied the established LNCaP prostate cancer progression model. Herein we show that the bone metastatic derivative cell line, $\mathrm{C} 4-2 \mathrm{~B}$, displays changes in adhesion to collagen type I and invasion into collagen type I. Moreover, we found that these changes were concomitant with activation of the FAK/src/paxillin/Rac/JNK signaling pathway and increased activity of matrix metalloproteinases (MMPs)-2 and -9. Inhibition of src and JNK resulted in inhibition of adhesion and invasion, and deactivation of the signaling molecules in the identified pathway as well as reduced activity of MMPs. Additionally, we found a pivotal role for the integrin $\alpha 2$ subunit since lateral redistribution and clustering were responsible for activation of the downstream signaling and function blocking of the integrin $\alpha 2$ subunit resulted in poor adhesion and inhibition of invasion. In conclusion, our results suggest that invasion of prostate cancer cells can be ascribed to reorganization and clustering of integrin $\alpha 2$ subunits, resulting in activation of associated $\mathrm{FAK} / \mathrm{src} /$ paxillin/Rac/JNK, leading to increased activity of MMPs and thus invasion.
\end{abstract}

Correspondence to: Dr Severine Van Slambrouck and Dr Wim F.A. Steelant, Department of Chemistry, Laboratory of Biochemical and Biomedical Research, New Mexico Tech, 801 Leroy Place, Socorro, NM 87801, USA

E-mail: severine@nmt.edu; steelant@nmt.edu

${ }^{*}$ Contributed equally

Abbreviations: ECM, extracellular matrix; FAK, focal adhesion kinase; JNK, c-jun $\mathrm{NH}_{2}$ terminal kinase; MAPK, mitogen-activated protein kinase; MMP, matrix metalloproteinase

Key words: adhesion, invasion, extracellular matrix, integrin, signaling, prostate cancer

\section{Introduction}

The most lethal aspect of cancer is the metastatic spread of primary tumors to distant sites. Despite intense investigation into the underlying process, the exact mechanisms of local invasion and the formation of metastases remain elusive. Biological and biochemical insight into this process would allow the development of new therapeutic targets that can efficiently prevent this process (1). It is generally accepted that changes in the expression of genes, encoding molecules that are involved in cell adhesion, migration and the production of proteinases that degrade the surrounding extracellular matrix (ECM), underscore metastasis $(2,3)$. However, recent studies demonstrated that tumor malignancy may also result from differential organization and clustering of membrane proteins and lipids and their assembly with signaling molecules, thereby activating downstream signaling pathways leading to invasion (4-7).

Signal transduction molecules, such as the non-receptor tyrosine kinases (NRTKs), focal adhesion kinase (FAK) and src are found to play important roles in tumor metastases. Catalytic activity of both FAK and src are often upregulated in malignant human tumor samples. These changes correlate with the acquisition of an invasive cell phenotype and enhanced metastasis (8). FAK is linked to signaling events between cells and the ECM and plays an important role in relaying signals to numerous targets generated by a variety of cell surface molecules, predominantly integrins amongst others such as growth factor and G-protein coupled receptors and tetraspanins (9-12). Integrins are a family of $\alpha / \beta$ heterodimeric receptors regulating processes such as proliferation, survival, invasion and metastasis. They mediate attachment to ECM proteins and link the extracellular environment with intracellular signaling events (13). FAK associates with the cytoplasmic tail of the $B$ subunits and becomes activated at Tyr397 upon integrin ligation. Subsequent binding of FAK to src leads to the formation of an active and transient FAK-src signaling complex (14) that in turn promotes src-mediated phosphorylation of FAK within the kinase domain activation loop (Tyr576 and Tyr577), as well as phosphorylation of FAK at the C-terminal domain residues, Tyr861 and Tyr925 (15-17). Alternatively, the non-receptor tyrosine kinase src may directly associate with integrin $\beta$ tails (18). The activated FAK (Tyr397)/src signaling complex allows the activation of multiple downstream targets, including the mitogen-activated 
protein kinase (MAPK)-cascade through FAK Tyr925, p130Cas via FAK Tyr861 or paxillin by FAK Tyr576 (19-22), all leading to increased expression and secretion of MMP-2 and MMP-9 (23-25).

In the present study, we used the LNCaP progression model, a culture to animal system, to elucidate changes in the organization and/or expression of membrane proteins and their influence on associated signaling pathways as cancer cells acquire the invasive phenotype. The LNCaP model allows the investigation of differences in invasive behavior as these cell lines vary in metastatic potential but share a common genetic background. In addition, phenotypic and genotypic characterization of these cell lines revealed a remarkable resemblance to the clinical progression of human prostate cancer (26). We previously showed that the bone metastatic prostate cancer cells, C4-2B, invade into collagen type I (27) which provided the opportunity to further explore the underlying mechanisms of invasion. We report in this study that the adhesive and invasive behavior of bone metastatic C4-2B cells are mediated through the lateral reorganization of the integrin $\alpha 2$ subunit and its association and activation of the FAK/src/paxillin/ JNK/Rac pathway and results in enhanced activation of matrix metalloproteinases, MMP-2 and MMP-9.

\section{Materials and methods}

Antibodies and other reagents. Antibodies directed to the distinct phosphorylation sites of FAK (Tyr397, Tyr576 and Tyr861), p-src, Rac, and p-Rac were from Invitrogen (Carlsbad, CA). Mouse anti-FAK and anti-src monoclonal antibodies $(\mathrm{mAb})$ were from Transduction Laboratories (San Jose, CA). Rabbit anti-JNK and anti-p-JNK were obtained from Cell Signaling Technologies (Beverly, MA). Antibodies against the different integrin subunits and receptors, paxillin and p-paxillin were from Millipore (Billerica, MA). Antibodies to MMP-2, MMP-9 and FAK Tyr925 were from Santa Cruz Biotechnology, Inc. (Santa Cruz, CA). Secondary biotinylated anti-rabbit and anti-mouse, FITC-labeled antimouse and FITC-labeled anti-rabbit secondary antibodies were from Vector Laboratories (Burlingame, CA). The src kinase inhibitor, 4-amino-1-tert-butyl-3-(1'-naphthyl) pyrazolo[3,4-d] pyrimidine (PP1) and the JNK inhibitor II, Anthra[1,9-cd] pyrazol-6(2H)-one 1,9-pyrazoloanthrone (SP600125) were from EMD Chemicals, Inc. (Gibbstown, $\mathrm{NJ})$. BCA protein assay reagent kit was from Pierce (Rockford, IL). Vectastain ABC-AmP kit was obtained from Vector Laboratories.

Cell culture. The human prostate cancer LNCaP cells and the bone metastatic derivative cell line $\mathrm{C} 4-2 \mathrm{~B}$ were a kind gift from Dr M. Bisoffi (UNM, School of Medicine, NM) (26) and were grown in RPMI-medium supplemented with $5 \% \mathrm{FBS}, 100 \mathrm{IU} / \mathrm{ml}$ penicillin, $100 \mu \mathrm{g} / \mathrm{ml}$ streptomycin (Invitrogen) at $37^{\circ} \mathrm{C}$ equilibrated with $5 \% \mathrm{CO}_{2}$ in humidified air.

Cell adhesion assay. Cells were detached with trypsin/EDTA and resuspended at $5 \times 10^{5}$ cells/ml in RPMI supplemented with $2 \%$ FBS in the presence or absence of function blocking antibodies or pharmacological inhibitors. Cell suspension
(100 $\mu$ l) was added to collagen I-precoated 96-well plates (BD Biosciences, San Jose, CA). After $2 \mathrm{~h}$ incubation at $37^{\circ} \mathrm{C}$, wells were washed three times with PBS. The remaining cells were solubilized with $0.2 \%$ Triton X-100 and acid phosphatase activity was measured by addition of p-nitro-phenyl phosphate (Sigma). Absorbance values of the lysates were determined on a microplate reader at $405 \mathrm{~nm}$.

Collagen type I invasion assay. Six-well plates were filled with $1.25 \mathrm{ml}$ neutralized type I collagen (0.09\%, Millipore) and incubated for $1 \mathrm{~h}$ at $37^{\circ} \mathrm{C}$ to allow gelification. For invasion into collagen type I, cells were harvested using trypsin/EDTA and seeded on top of collagen type I gels. Cultures were incubated for $24 \mathrm{~h}$ at $37^{\circ} \mathrm{C}$ in the presence or absence of function blocking antibodies or pharmacological inhibitors. Numbers of cells penetrating into the gel or remaining at the surface were counted, using an inverted microscope and expressed as the invasion index, being the percentage of invading cells over the total number of cells (28).

Fluorescence immunostaining. Cells were grown on glass cover slips (diameter, $12 \mathrm{~mm}$ ) placed in 24-well plates. The glass cover slips were removed, washed and fixed with methanol. Next, fixed cells were washed and incubated with appropriate primary antibodies, followed by incubation with FITC-labeled secondary antibodies. Stained cells were mounted with Glycergel mounting medium (Dako Corp., Carpinteria, CA) containing 1\% 1,4-diazabicyclo[2.2.2] octane (fluorescence stabilizer) and images were acquired using a fluorescence microscope (Olympus IX51 with Olympus U-CMAD3 camera). Control stainings were performed without primary antibody to measure possible cross-reaction or non-specific binding.

Western blotting. Cell lysates were made from $70 \%$ confluent cultures that were untreated or pretreated with inhibitors, using $0.5 \mathrm{ml}$ lysis buffer containing $1 \%$ Triton X-100, $1 \%$ NP-40 and the following inhibitors: aprotinin $(10 \mu \mathrm{g} / \mathrm{ml})$, leupeptin $(10 \mu \mathrm{g} / \mathrm{ml})$, PMSF $(1.72 \mathrm{mM}), \mathrm{NaF}(100 \mathrm{mM}), \mathrm{NaVO}_{3}$ $(500 \mu \mathrm{M})$, and $\mathrm{Na}_{4} \mathrm{P}_{2} \mathrm{O}_{7}(500 \mu \mathrm{g} / \mathrm{ml})$. Aliquots of lysates, containing $30 \mu \mathrm{g}$ of protein, were boiled for $5 \mathrm{~min}$ in SDSPAGE sample buffer containing 5\% $\beta$-mercaptoethanol, electrophoresed on $7.5 \%$ or $12 \%$ SDS-PAGE and transferred to PVDF membranes (Immobilon-P) (Bio-Rad Laboratories, Hercules, CA). After transfer, membranes were incubated with relevant primary antibodies followed by incubation with secondary biotinylated antibodies and developed by ECL (Vectastain ABC-AmP) detection kit. Some of the membranes were stripped at $50^{\circ} \mathrm{C}$ for $30 \mathrm{~min}$ in $100 \mathrm{mM} \beta$-mercaptoethanol, $2 \%$ SDS, $62.5 \mathrm{mM}$ Tris- $\mathrm{HCl}$ (pH 6.8) and reblotted with appropriate antibodies, for control of equal loading. Membranes were imaged on the BioChemi System and analysis software (UVP, Upland, CA).

Flow cytometry analysis. Cells were detached and suspended as single cells using $10 \mathrm{mM}$ EDTA and $20 \mathrm{mM}$ HEPES buffer in the appropriate medium. The EDTA was neutralized with $\mathrm{CaCl}_{2}$ and $\mathrm{MgSO}_{4}$ and washed again with medium containing $0.1 \%$ BSA. Cells $\left(2.5 \times 10^{5}\right)$ were incubated with the relevant primary antibodies, followed by secondary FITC-labeled 
antibodies. After washing, $1 \times 10^{4}$ stained cells were analyzed for fluorescence using the Cell Lab Quanta SC MPL (Beckman Coulter, Miami, FL). Stainings without primary antibody were used as controls.

Co-immunoprecipitation of cell surface molecules. Cells at $70 \%$ confluency, untreated or pretreated with inhibitors, were lysed, as described under 'Western blotting'. Lysates, containing 1,000-1,500 $\mu \mathrm{g}$ protein, were mixed with protein G-Sepharose beads (Amersham Biosciences, NJ) to preclear non-specific binding. Antibodies to relevant cell surface molecules were added to the collected supernatant and rotated at $4^{\circ} \mathrm{C}$ overnight. Subsequently, protein G-Sepharose beads were used to recover the immunocomplexes. Immunoprecipitates were resolved in $150 \mu 1$ SDS-PAGE sample buffer and heated to $95^{\circ} \mathrm{C}$ for $5 \mathrm{~min}$. The supernatants were then subjected to SDS-PAGE, transferred electrophoretically to PVDF membranes, incubated with relevant antibodies and imaged and analyzed on the BioChemi System (UVP).

In-gel gelatinase assay. Gelatin zymography was performed, as described previously (29). Briefly, medium of subconfluent cultures, in the presence or absence of pharmacological inhibitors or function blocking antibodies were collected, clarified by centrifugation and resolved in non-reducing gels containing gelatin $(1.5 \mathrm{mg} / \mathrm{ml})$ and processed for identification of gelatinase activity.

Statistics. All treatments were matched and carried out at least three times. Data were analyzed using Excel, for determination of mean, SD and Student's t-test (95\%). Intensity of the immunoblotted bands was quantified by densitometry, using statistical software Scion Image (Scion Corporation, Frederick, MD).

\section{Results}

Differences in adhesion, invasion and proteinase activity of LNCaP and C4-2B cells. To determine differences between LNCaP cells and the derivative cell line C4-2B, the cell adhesion to collagen I, the invasion into collagen I and in-gel gelatinase assays were performed. Fig. $1 \mathrm{~A}$ and $\mathrm{B}$ illustrate that $\mathrm{C} 4-2 \mathrm{~B}$ cells show a stronger adhesion to collagen I and are highly invasive into collagen I as compared to LNCaP cells. In several cancer cell types the gelatinases MMP-2 and MMP-9 correlate with tumor cell invasion and thus are involved in tumor progression (30). As shown in Fig. 1C the MMP-2 and MMP-9 activities in C4-2B cells are more elevated than in LNCaP cells. Overall, these results indicate the differences between the two cell lines and provide a basis for further investigation.

Src activity promotes adhesion and invasion. Src has been implicated in tumor progression of several cancer types and recent studies showed a putative role in prostate cancer progression $(31,32)$. To examine whether src kinase is involved in the observed increased adhesion to collagen I and invasion into collagen I, the cells were pretreated with PP1, the pharmacological inhibitor of src kinase activity. The data in Fig. 2A reveals that PP1 reduces the binding of C4-2B cells
A

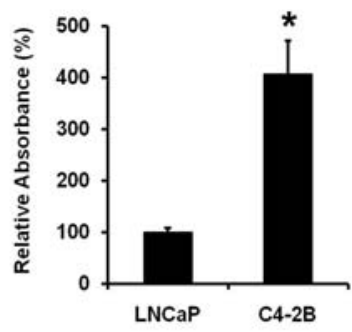

B

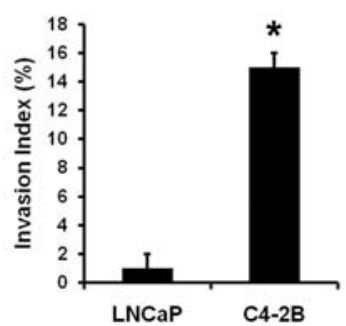

C
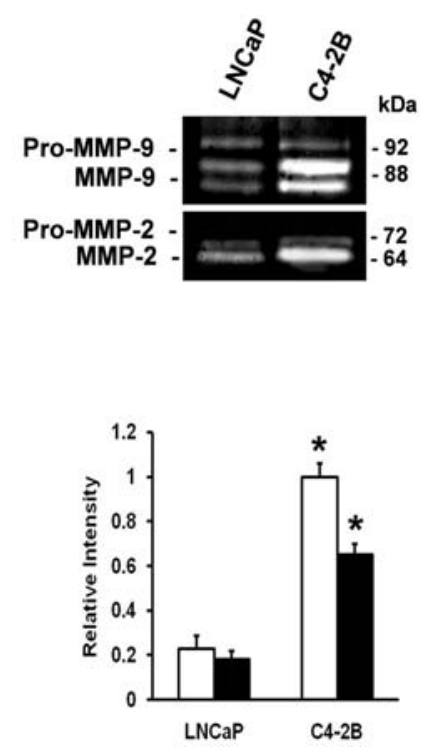

Figure 1. Adhesion, invasion and proteinase activity of prostate cancer cells (A) Adhesion to collagen I. Cells $/ 100 \mu 1\left(5 \times 10^{4}\right)$ were seeded in a collagen I precoated 96-well plate. After $2 \mathrm{~h}$, the cells were washed and acid phosphatase activity was measured. The percentage binding was calculated by subtracting non-specific binding. (B) Invasion into collagen I. Cells $\left(1 \times 10^{4}\right)$ were seeded on top of collagen type I gels and cultured for $24 \mathrm{~h}$. The invasion index expresses the percentage of invading cells into collagen type I over the total number of cells. (C) Activity of MMP-9 (open bars) and MMP-2 (closed bars) by gelatin zymography. Conditioned media prepared from subconfluent cultures were collected, resolved in non-reducing gels containing gelatin $(1.5 \mathrm{mg} / \mathrm{ml})$ and processed for zones of gel degradation activity. All data are means \pm SD from three independent experiments, asterisks indicate statistical difference from parental LNCaP cells $(\mathrm{P}<0.05)$.

to collagen I and blocks the invasiveness of $\mathrm{C} 4-2 \mathrm{~B}$ cells into collagen type I. Accordingly, increased activation level of src is found in C4-2B cells, which is abolished by PP1. No alteration in src expression level is found amongst the two cell lines (Fig. 2B). Fig. 2C shows the reduced activity levels of MMP-2 and MMP-9 upon treatment with PP1. In summary, our data indicate that src kinase is involved in $\mathrm{LNCaP}$ prostate cancer progression.

Implication of src in phosphorylation sites on FAK. Next, we examined the status of FAK phosphorylation at Tyr397, the FAK autophosphorylation and activation site, as well as the other FAK tyrosine residues that are src-dependent in LNCaP and C4-2B cells (15-17). As shown in Fig. 3, the total FAK expression levels are equal in the two cell lines, while the activity of FAK Tyr397 is greatly enhanced in C4-2B and not in LNCaP cells. Similar observations are made for the phosphorylation status of FAK Tyr576 while no changes in activity level are observed for FAK Tyr861 (data not shown) and Tyr 925 is somewhat increased in C4-2B cells (data not shown). Pretreatment with the inhibitor PP1 prevents srcdependent phosphorylation at Tyr576 in C4-2B cells.

Src-FAK signaling enhances paxillin, Rac and JNK activation. The src-FAK signaling complex activates multiple downstream signaling elements via distinct tyrosine residues on FAK 
A
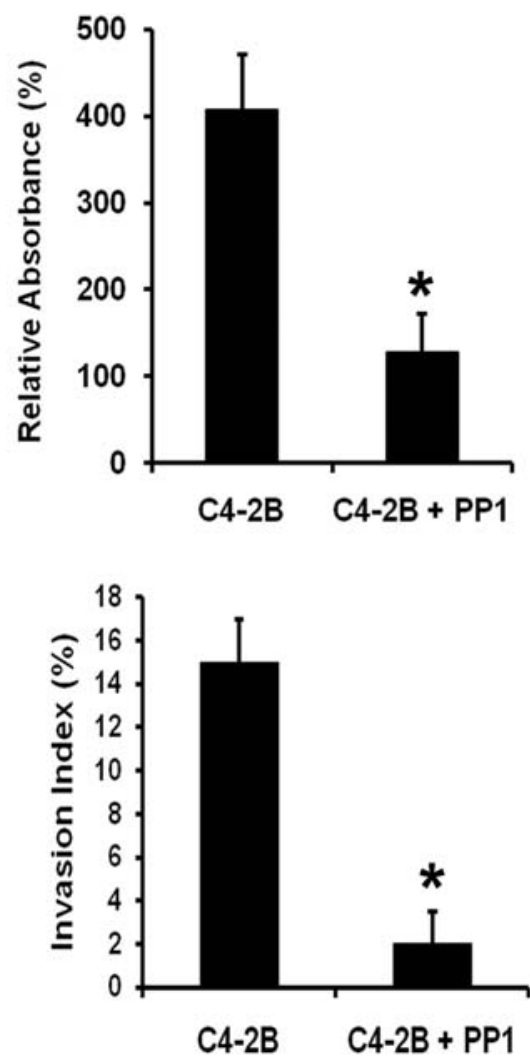

B
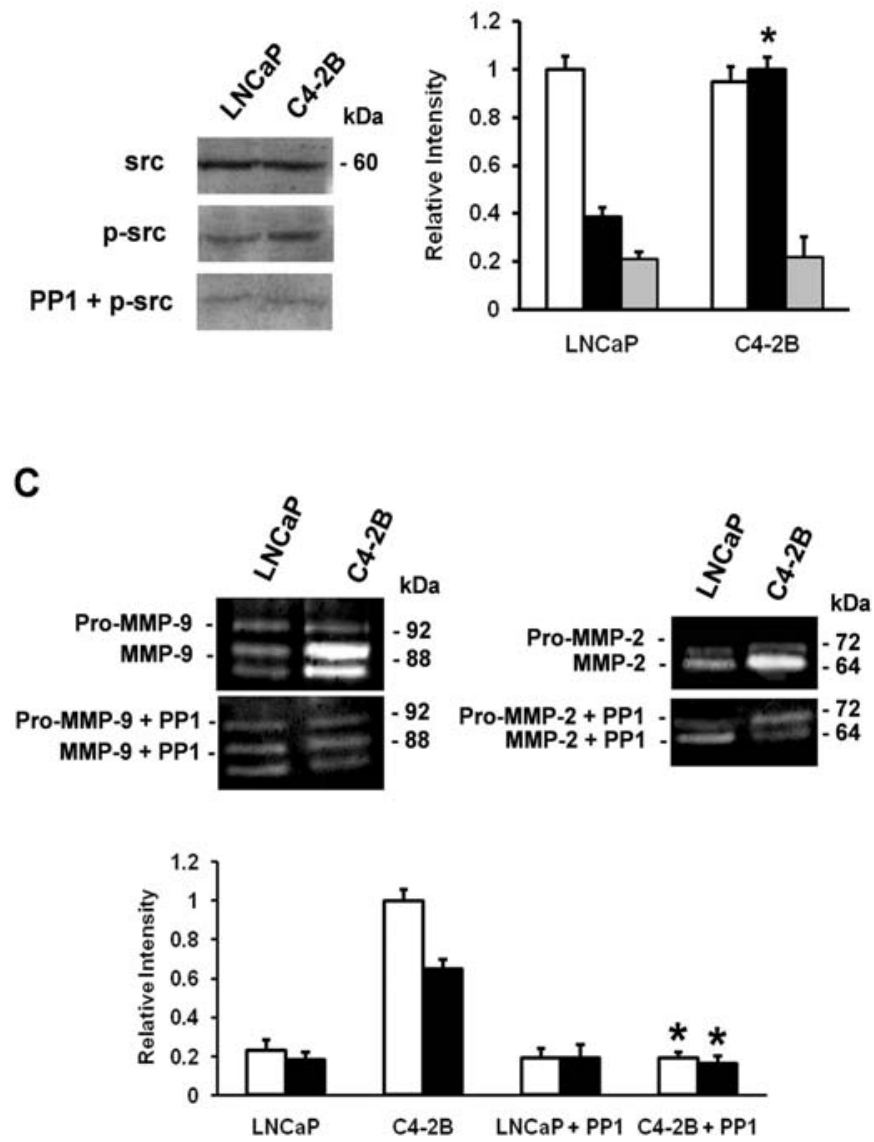

Figure 2. Src in adhesion, invasion and protease activity of prostate cancer cells. (A) Upper panel, adhesion to collagen I. Cells/100 $\mu 1$, (5x10 $)^{4}$ untreated or treated with PP1 $(20 \mu \mathrm{M})$, were seeded in a collagen I precoated 96-well plate. After $2 \mathrm{~h}$, the cells were washed and acid phosphatase activity was measured. The percentage binding was calculated by subtracting non-specific binding. Lower panel, invasion into collagen I. Cells $\left(1 \mathrm{x} 10^{4}\right)$ in the presence or absence of $20 \mu \mathrm{M}$ PP1, were seeded on top of collagen type I gels and cultured for $24 \mathrm{~h}$. The invasion index expresses the percentage of invading cells into collagen type I over the total number of cells. All data are means \pm SD from three independent experiments, asterisks indicate statistical difference from untreated C4-2B cells $(\mathrm{P}<0.05)$. (B) Western blot analysis of activated src (p-src). Cells were pretreated for 30 min with PP1 $(20 \mu \mathrm{M})$, where indicated. Cell lysates containing $30 \mu \mathrm{g}$ protein were further analyzed by 7.5\% SDS-PAGE, using the corresponding primary antibodies. The membranes were reblotted after stripping with anti-src for total src expression and protein loading. Densitometric band analysis corresponding to phosphorylated src (p-src) (closed bars), vs. total src (open bars) and treatment with PP1 (gray bars) (relative intensity). All data are means \pm SD from three independent experiments, asterisks indicate statistical difference from parental LNCaP cells $(\mathrm{P}<0.05)$. (C) Activity of MMP-2 (closed bars) and MMP-9 (open bars) by gelatin zymography. Conditioned media prepared from subconfluent cultures in the presence or absence of $20 \mu \mathrm{M}$ PP1, were collected, resolved in non-reducing gels containing gelatin (1.5 mg/ml) and processed for zones of gel degradation activity. All data are means \pm SD from three independent experiments, asterisks indicate statistical difference from untreated C4-2B cells $(\mathrm{P}<0.05)$.

(19-22). Phosphorylation at Tyr576 in the kinase activation loop leads to hyperphosphorylation of paxillin that after complex formation with Crk and DOCK180 activates the small GTPase Rac $(20,21)$, which in many cell types regulates JNK activation (33). Fig. 4A (left) shows the enhanced phosphorylation levels of paxillin, Rac and JNK in C4-2B cells as compared to LNCaP as well as the total levels of paxillin, Rac and JNK levels in all cell lines. When the cells are pretreated with PP1, the activity levels of paxillin, Rac, and JNK decrease in C4-2B cells (Fig. 4A, right) to a similar level as the parental LNCaP cells. The importance of JNK activation promoting the observed effects is further confirmed by inhibition of adhesion to collagen I, invasion into collagen I, activation of MMP-2 and MMP-9, and activity levels of JNK, by the pharmacological inhibitor of JNK kinase SP600125 (Fig. 4B). In conclusion, the data indicate a continuously active signaling pathway in C4-2B cells.
Expression and reorganization of integrins. Since src and FAK are recognized as two critical mediators of integrin signaling, we addressed whether integrins were implicated in the activation of FAK and the associated downstream signal transducers in collagen I adhesion and invasion, and MMP activity. $\alpha 1, \beta 1$ and $\alpha 2$ are the major collagen receptors subunits binding collagen I in the ECM (34). Next, we examined these integrin subunits for their total expression levels by Western blotting and their cell surface expression levels by flow cytometry while reorganization was investigated by immunofluorescence microscopy. The Western blotting results reveal that the expression of the integrin $\alpha 2$ subunit is faintly enhanced in $\mathrm{C} 4-2 \mathrm{~B}$ cells as compared to $\mathrm{LNCaP}$ cells, while the expression levels of the $B 1$ and $\alpha 1$ subunits are similar for all cell lines (Fig. 5A). The total expression level of the $\alpha 1 \beta 1$ receptor is equal in all cell lines (data not shown) and the total expression level of the $\alpha 2 \beta 1$ receptor is only 

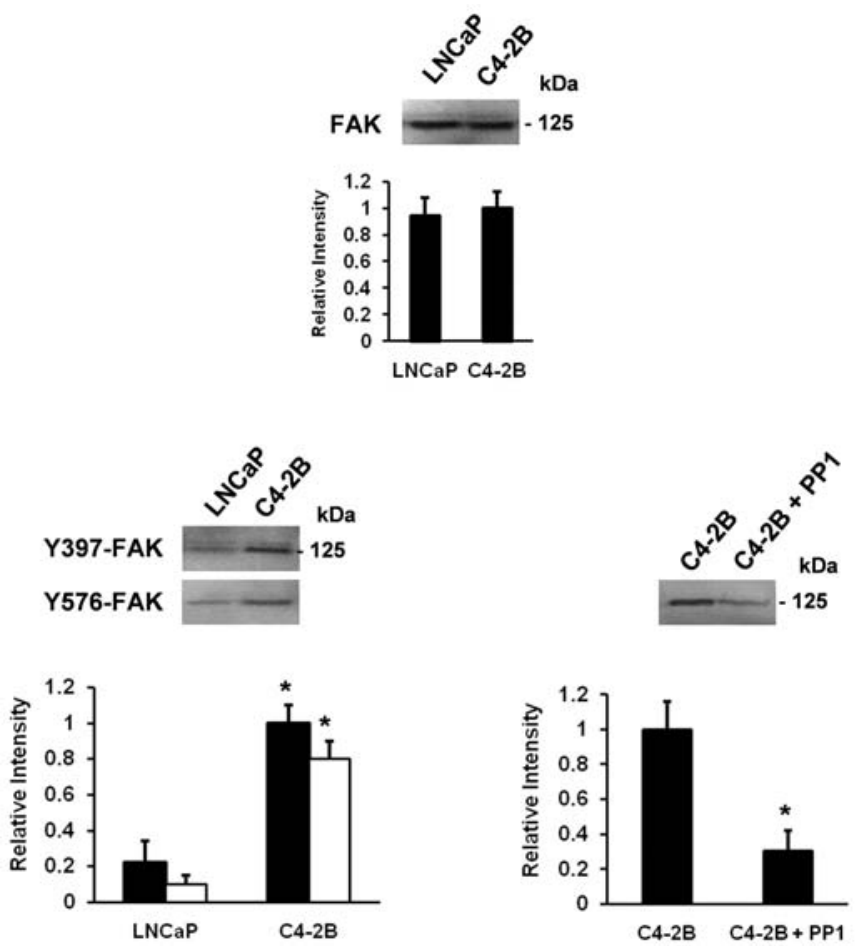

Figure 3. Src in phosphorylation sites on FAK. Western blot analysis of FAK and activated FAK (p-FAK) at Tyr397 and Tyr576. Cells were pretreated for 30 min with PP1 $(20 \mu \mathrm{M})$, where indicated (right panel). Cell lysates containing $30 \mu \mathrm{g}$ protein were analyzed by $7.5 \%$ SDS-PAGE, using the corresponding primary antibodies. The membranes were reblotted after stripping with anti-FAK for total FAK expression and protein loading (top panel). Densitometric band analysis corresponding to FAK (top panel), p-FAK Tyr397 (left panel, closed bars) and Tyr576 (left panel, open bars) and treatment with PP1 (right panel) (relative intensity). All data are means \pm SD from three independent experiments, asterisks indicate statistical difference from parental $\mathrm{LNCaP}$ or from untreated $\mathrm{C} 4-2 \mathrm{~B}$ cells $(\mathrm{P}<0.05)$.

slightly increased in C4-2B cells, which is not significantly different (Fig. 5A). As shown in Fig. 5B the cell surface expression of the integrin subunits and the $\alpha 2 \beta 1$ receptor are identical in LNCaP and C4-2B cells. Immunofluorescence staining demonstrates that the integrin $\alpha 2$ and $\beta 1$ subunits are differentially organized in the distinct cell lines, whereas no differences in pattern are observed for the integrin $\alpha 1$ subunit. Fig. 5C shows that integrin $\beta 1$ and $\alpha 2$ subunit clusters are present in $\mathrm{C} 4-2 \mathrm{~B}$ cells and not in LNCaP cells. In addition, staining of the $\alpha 2 \beta 1$ receptor reveals a similar organization pattern as the integrin $\alpha 2$ subunit.

Integrin a2 subunit mediates adhesion and invasion and activates the downstream pathway. We next studied the impact of the differential organization of the integrin $\alpha 2$ subunits on adhesion and invasion. Fig. 6A shows that using a function blocking antibody against the $\alpha 2$ subunit or the $\alpha 2 \beta 1$ receptor blocks adhesion to collagen $\mathrm{I}$ and invasion into collagen I, while antibodies against the $\alpha 1$ and $\beta 1$ subunits do not affect any of the observed effects (data not shown). Further implication of the integrin $\alpha 2$ subunit is confirmed by co-immunoprecipitation experiments revealing the presence of active FAK, src, paxillin, Rac, and JNK in $\alpha 2$ immunoprecipitates of $\mathrm{C} 4-2 \mathrm{~B}$ cells, comparable to the Western blotting results, as well as the unactivated signal transducers in the two cell lines (Fig. 6B). No activated signal transducers could be detected in the immunoprecipitates of the other integrin subunits and the $\alpha 2 \beta 1$ receptor and this for the two cell lines (data not shown). These results point out a pivotal role of the integrin $\alpha 2$ subunit in adhesion and invasion.

\section{Discussion}

Tumor cells that form metastases must interact with the extracellular environment in order to migrate toward the underlying lymph or blood vessel. Important classes of molecules within the invasive front include cell adhesion molecules and matrix metalloproteinases (35).

At present, a dominant concept in tumor biology is that tumor progression involves alterations in expression levels of cell adhesion molecules, proteinases and signaling molecules, especially activation of oncogenes and anti-oncogenes $(2,3)$. Undoubtedly, these molecules play a role in cancer and cancer progression. However, there is also increasing evidence that changes in cellular phenotype are strongly affected by differential organization and clustering of membrane lipids and proteins, and their assembly with signaling molecules, responsible for the activation of downstream signaling pathways. This has recently been demonstrated for MSGb5, integrin $\alpha 1$ as well as for GM2, acting through complex formation with CD82 and cMet (4-7). This concept was further tested in the isogenic $\mathrm{LNCaP}$ progression model (LNCaP and C4-2B).

In the present study, we demonstrate that increasing activity levels of FAK and src in the derivative cell line C4-2B compared to LNCaP cells correlate with their ability to adhere to and invade the collagen I and are linked to increased activity of matrix metalloproteinases. These results are in accordance with clinical studies showing that bone metastatic human prostate cancer cells display an activated FAK-src signaling complex compared with prostate cancer cells that are metastatic to other visceral sites such as the lymph node (36). Furthermore, we show that the downstream targets of the FAK-src signaling complex include paxillin, Rac, and JNK via activation of FAK Tyr576, which is in line with previous studies reporting that the dual kinase FAK-src complex is responsible for activation of additional tyrosine residues on FAK (20). Additionally, it has been shown that FAK activation at Tyr576 results in a hyperactive paxillin and activation of JNK downstream of Rac (33) resulting in enhanced activity levels of MMP-2 and MMP-9 (24,25). The significance of the identified signaling pathway is further confirmed by tyrosine kinase inhibitors, PP1 and SP600125, not only inhibiting the adhesive and invasive behavior of C4-2B cells, but also decreasing the activity levels of all signaling molecules involved and reducing the activity levels of the matrix metalloproteinases. This is consistent with other studies using these inhibitors to affect cell adhesion, migration, invasion and protease activity $(22,24,37)$.

Subsequently, we examined whether these molecules were involved in integrin-mediated signaling given that the major collagen I binding receptors belong to the family of integrins. Integrins are $\alpha / \beta$ heterodimeric cell surface receptors that mediate attachment to the ECM and link the extracellular 
A
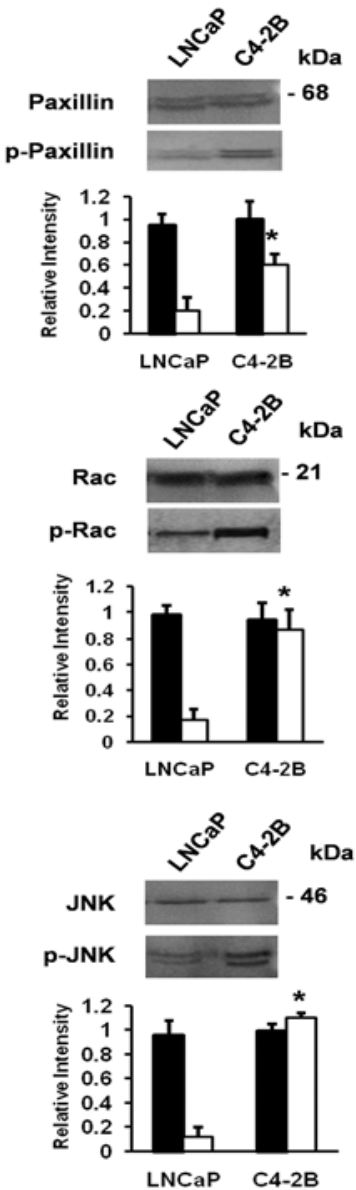
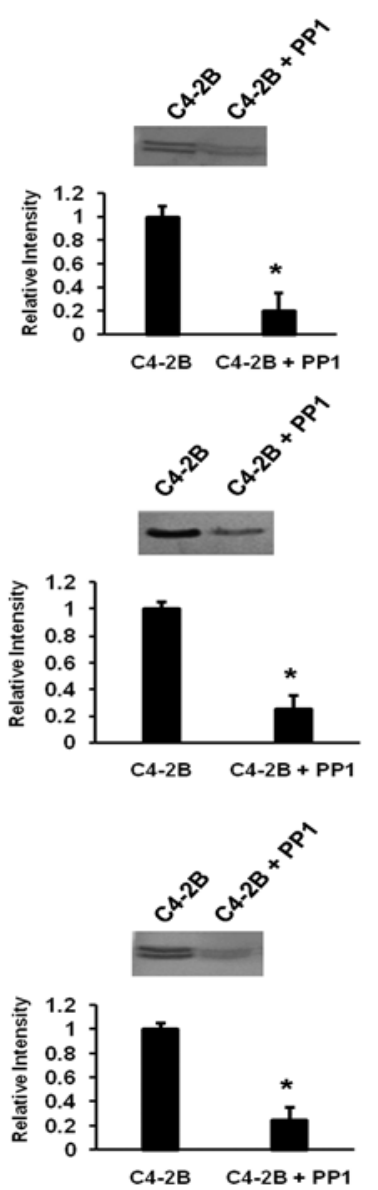

B
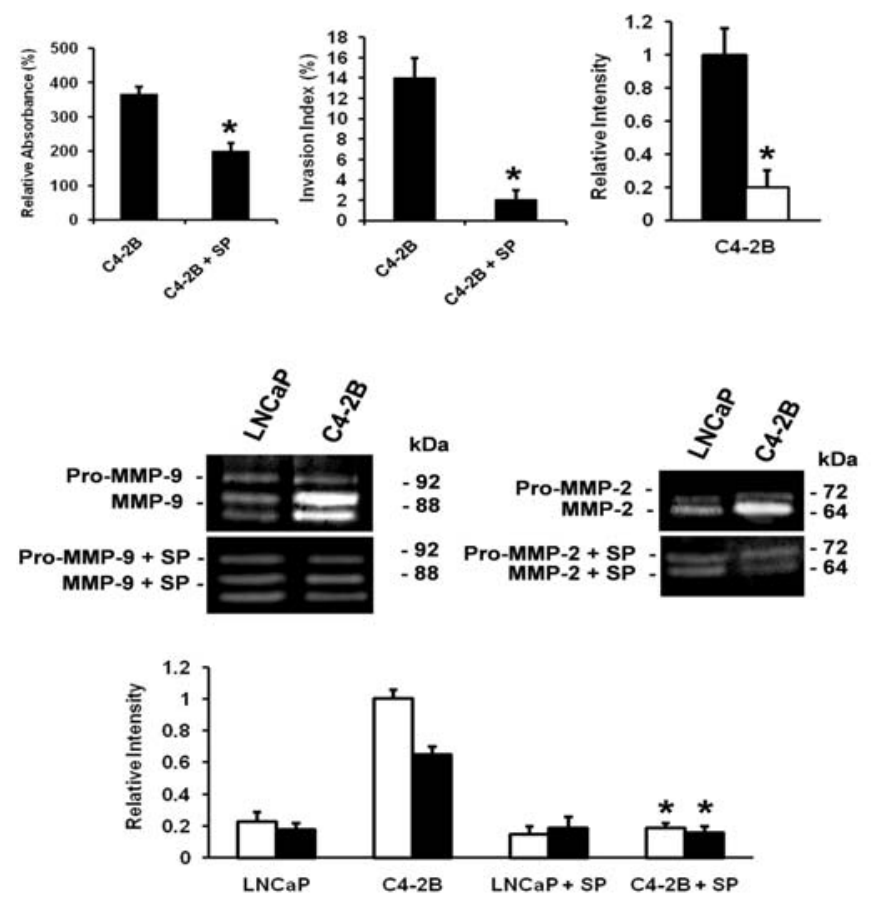

Figure 4. Src-FAK signaling activates paxillin, Rac and JNK. (A) Left panel, Western blot analysis of activated paxillin, Rac and JNK. Cells were pretreated for 30 min with PP1 $(20 \mu \mathrm{M})$ (right panel), where indicated. Cell lysates containing $30 \mu \mathrm{g}$ protein were further analyzed by $7.5 \%$ SDS-PAGE, using the corresponding primary antibodies. The membranes were reblotted after stripping with anti-paxillin, anti-Rac, and anti-JNK for total paxillin, Rac, and JNK expression and protein loading (left panel). Densitometric band analysis corresponding to p-paxillin, p-Rac, and p-JNK versus total protein in the cell lysates (left panel) and treatment with PP1 (right panel) (relative intensity). All data are means \pm SD from three independent experiments, asterisks indicate statistical difference from parental LNCaP or from untreated C4-2B cells $(\mathrm{P}<0.05)$. (B) Upper panel, left, adhesion to collagen I. Cells/100 $\mu 1\left(5 \times 10^{4}\right)$ untreated or treated with SP600125 $(10 \mu \mathrm{M})$, were seeded in a collagen I precoated 96-well plate. After $2 \mathrm{~h}$, the cells were washed and acid phosphatase activity was measured. The percentage binding was calculated by subtracting non-specific binding. Upper panel, middle, invasion into collagen I. Cells (1x $10^{4}$ ) in the presence or absence of $10 \mu \mathrm{M} \mathrm{SP} 600125$, were seeded on top of collagen type I gels and cultured for $24 \mathrm{~h}$. The invasion index expresses the percentage of invading cells into collagen type I over the total number of cells. All data are means \pm SD from three independent experiments, asterisks indicate statistical difference from parental LNCaP cells $(\mathrm{P}<0.05)$. Upper panel, right, Western blot analysis of activated JNK (p-JNK). Cells were pretreated for 30 min with SP600125 (10 $\mu \mathrm{M})$, where indicated. Cell lysates containing $30 \mu \mathrm{g}$ protein were analyzed by $7.5 \%$ SDS-PAGE, using the corresponding primary antibodies. Densitometric band analysis corresponding to phosphorylated JNK (p-JNK) (closed bars) and treatment with SP600125 (10 $\mu \mathrm{M})$ (open bars) (relative intensity). All data are means \pm SD from three independent experiments, asterisks indicate statistical difference from untreated C4-2B cells (P<0.05). Lower panel, activity of MMP-2 (closed bars) and MMP-9 (open bars) by gelatin zymography. Conditioned media prepared from subconfluent cultures untreated or treated with $10 \mu \mathrm{M}$ SP600125 as indicated, were collected, resolved in non-reducing gels containing gelatin (1.5 mg/ml) and processed for zones of gel degradation activity. All data are means \pm SD from three independent experiments, asterisks indicate statistical difference from untreated $\mathrm{C} 4-2 \mathrm{~B}$ cells $(\mathrm{P}<0.05)$.

environment with intracellular signaling events (13). The most prominent collagen type I receptors are $\alpha 1 \beta 1$ and $\alpha 2 \beta 1$ integrins (34). It has been reported that they are important in collagen I attachment and initiate motility and invasion (38). In $\mathrm{C} 4-2 \mathrm{~B}$ cells treated with function blocking antibodies against the integrin $\alpha 2$ subunit, cell adhesion and invasion are markedly suppressed compared to cells treated with antibodies against the $\alpha 1$ and $\beta 1$ subunits. In addition, activity inhibition is also achieved when an antibody against $\alpha 2 \beta 1$ is used, in contrast to $\alpha 1 \beta 1$ antibody. Western blotting and flow cytometric results further reveal that although a slight increase in the expression level of the $\alpha 2$ subunit is found, no significant changes could be detected in the cell surface expression levels of the different subunits and the heterodimers. Instead, imposing differences are found in the organization pattern of the $\alpha 2$ subunit and additionally the $\alpha 2 \beta 1$ receptor, while minor changes are found for the integrin $B 1$ subunit in $C 4-2 B$ cells. The demonstrated data are to a certain extent consistent with a previous study, namely that $\alpha 2 \beta 1$ mediates the increased binding of C4-2B cells to collagen I and stimulates invasion, which was ascribed to the abundant presence of integrin $\alpha 2 \beta 1$ (39). Conversely, our results point out that the increased adhesion and invasion is attributed to major alterations in the organizational status of the $\alpha 2$ subunit and consequently $\alpha 2 \beta 1$, rather than to increased expression. Moreover, we show that the identified signaling pathway is associated with the reorganization of $\alpha 2$ subunits. Relatively few integrin subunits have been identified to be involved in 
A
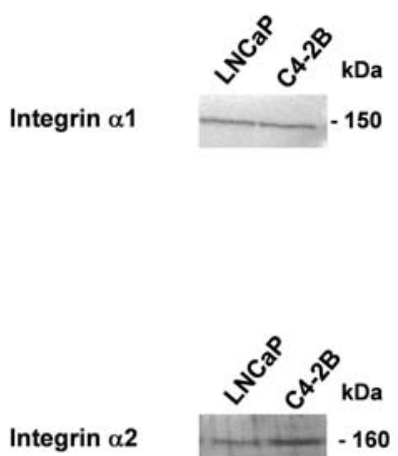

Integrin $\beta 1$

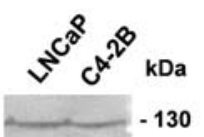

Integrin $\alpha 2 \beta 1$

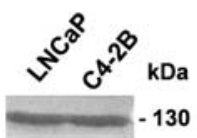

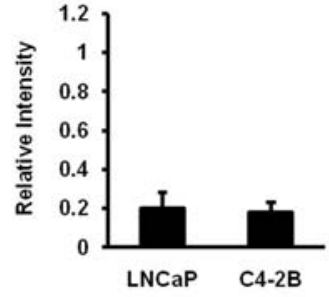
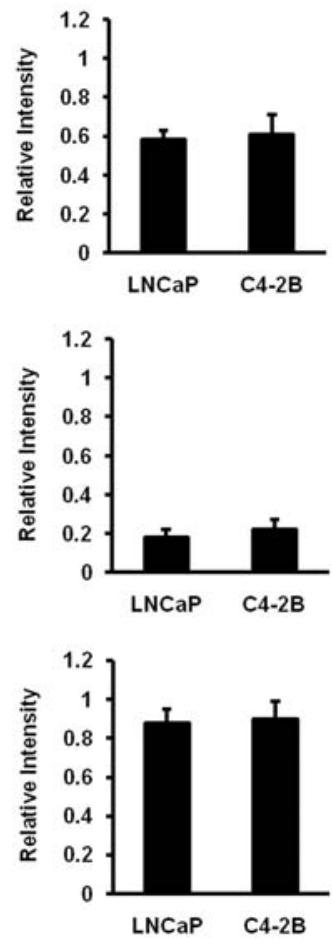

B

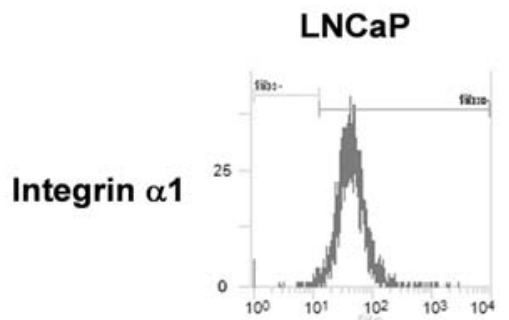

C4-2B

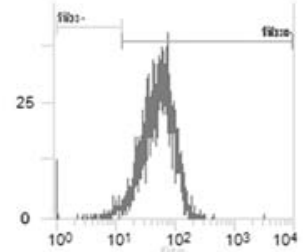

Integrin $\alpha 2$
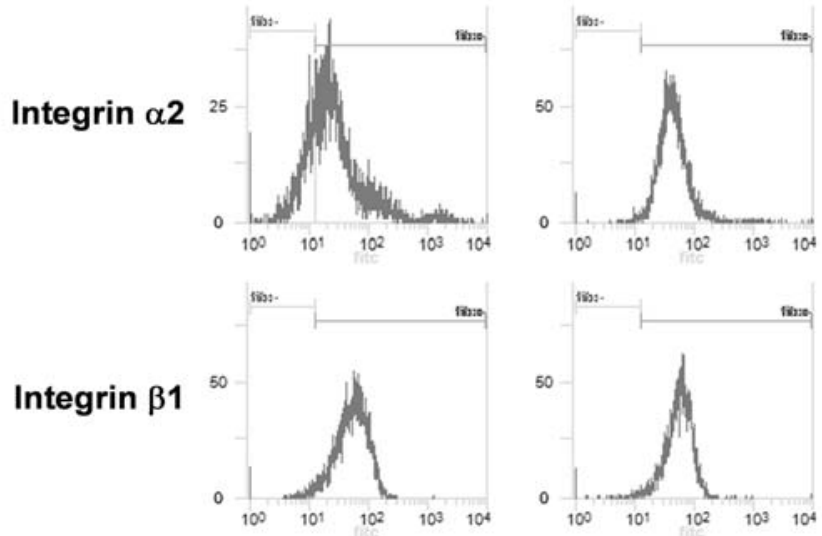

Integrin $\alpha 2 \beta 1$
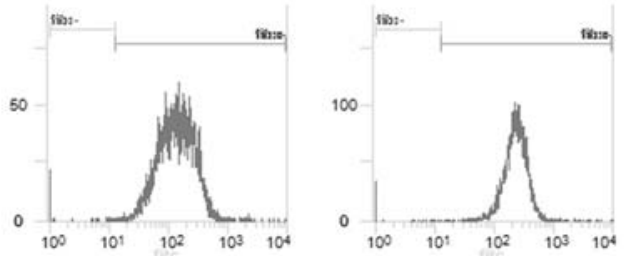

C
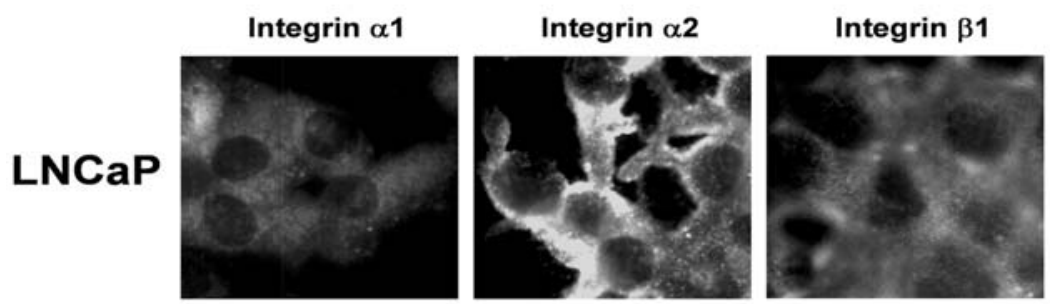

Integrin $\alpha 2 \beta 1$

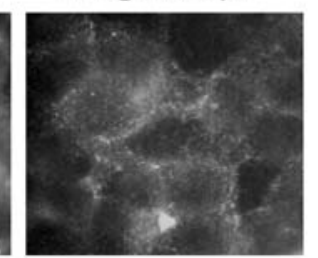

C4-2B
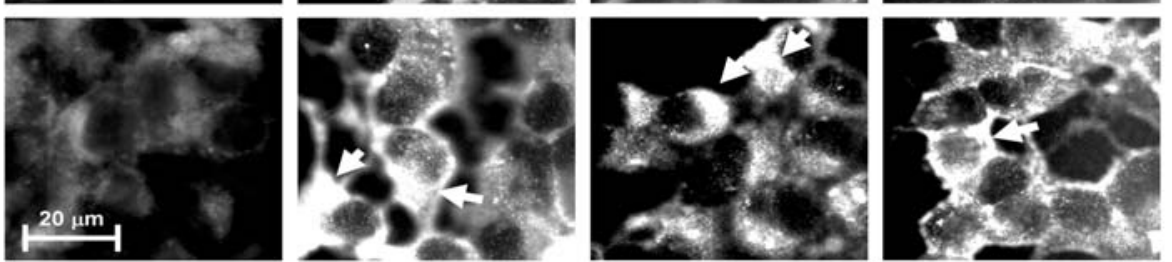

Figure 5. Expression and reorganization of integrins. (A) Western blot analysis for total expression levels of $\alpha 1-, \alpha 2-, \beta 1$-integrin subunits and $\alpha 2 \beta 1$ integrin. Cell lysates containing $30 \mu \mathrm{g}$ protein were analyzed by 7.5\% SDS-PAGE, using the corresponding primary antibodies. Densitometric band analysis corresponding to $\alpha 1, \alpha 2, \beta 1$ and $\alpha 2 \beta 1$ in the cell lysates (relative intensity). All data are means \pm SD from three independent experiments. (B) Cell surface expression levels of $\alpha 1-, \alpha 2-, \beta 1$-integrin subunits and $\alpha 2 \beta 1$ integrin. Single cell suspensions were stained by relevant primary integrin subunit or integrin receptor antibodies and FITC-labeled secondary antibodies. Control stainings were performed without primary antibody. Experiments were performed at least three times. (C) Organization of $\alpha 1-, \alpha 2-, \beta 1$-integrin subunits and $\alpha 2 \beta 1$ integrin by indirect fluorescence microscopy. Cells were grown on glass cover slips and stained by relevant primary integrin antibodies and FITC-labeled secondary antibodies. Arrows indicate the clusters of $\alpha 2-$ and $\beta 1$ integrin subunits and $\alpha 2 \beta 1$ integrin. Control stainings were performed without primary antibody. Experiments were performed at least three times.

signaling processes. To date, activation of integrin-mediated signaling pathways has mainly been connected to the $B$ subunit (13). Thus, identification of the integrin $\alpha 2$ subunit is an interesting target for FAK-src-dependent signaling and has recently been shown to be responsible for FAK-mediated ERK and calpain activation as well (40). To our knowledge, 
A
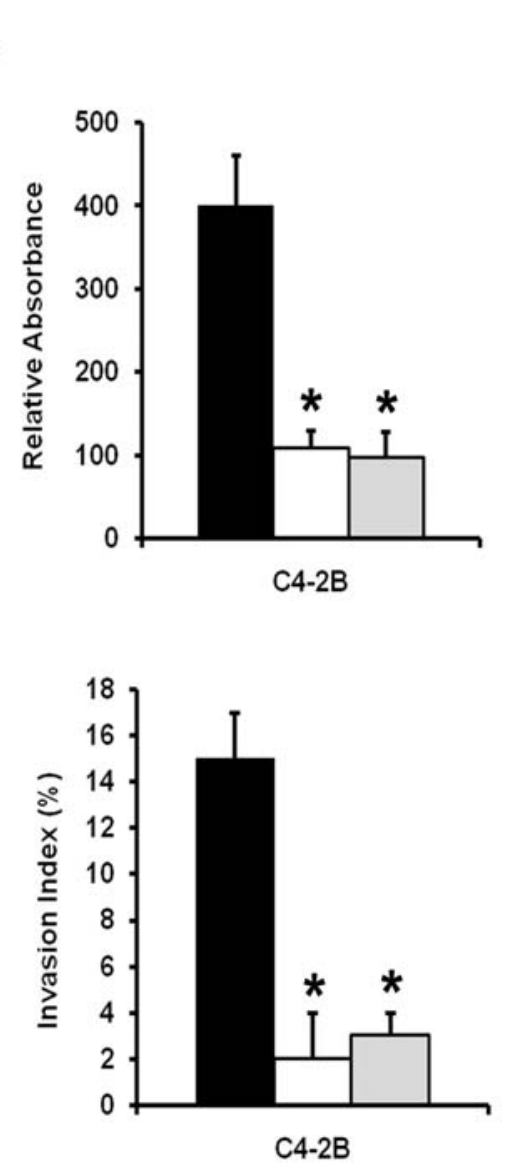

B
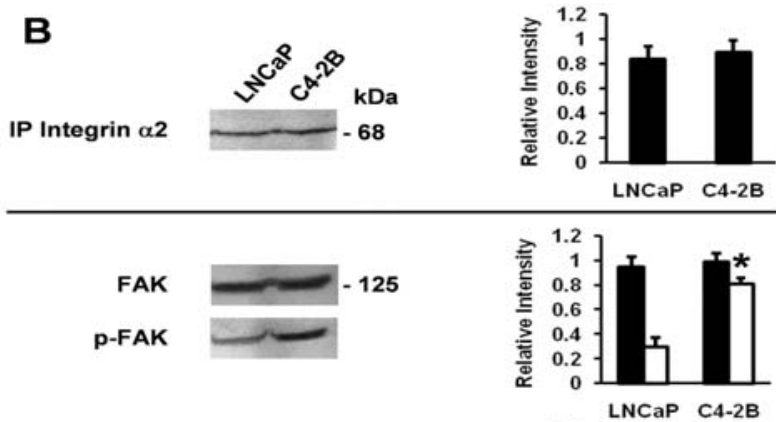

src

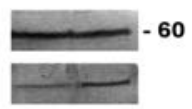

p-src
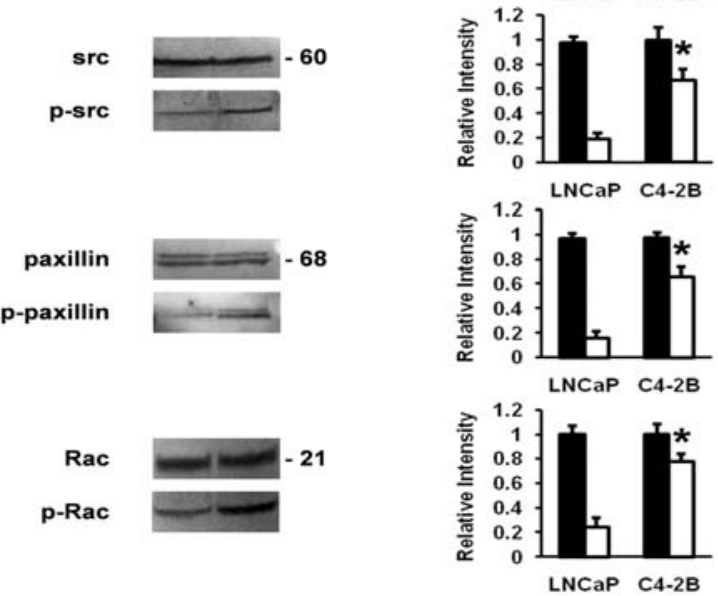

JNK

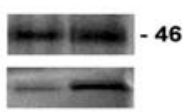

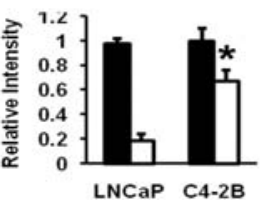

Figure 6. Integrin $\alpha 2$ subunit in adhesion, invasion and activation of the downstream pathway. (A) Upper panel, adhesion to collagen I. Cells/100 $\mu 1$ ( $5 \times 10^{4}$ ) untreated (closed bars) or treated for $30 \mathrm{~min}$ at room temperature with function blocking antibodies against the $\alpha 2$ integrin subunit (open bars) and $\alpha 2 \beta 1$ integrin (gray bars), were seeded in a collagen I precoated 96-well plate. After $2 \mathrm{~h}$, the cells were washed and acid phosphatase activity was measured. The percentage binding was calculated by subtracting non-specific binding. All data are means \pm SD from three independent experiments, asterisks indicate statistical difference from untreated $\mathrm{C} 4-2 \mathrm{~B}$ cells $(\mathrm{P}<0.05)$. Lower panel, invasion into collagen I. Cells $\left(1 \times 10^{4}\right)$ in the presence or absence (closed bars) of function blocking antibodies against $\alpha 2$ integrin subunits (open bars), $\alpha 2 \beta 1$ integrin (gray bars), were seeded on top of collagen type I gels and cultured for 24 h. The invasion index expresses the percentage of invading cells into collagen type I over the total number of cells. All data are means \pm SD from three independent experiments, asterisks indicate statistical difference from untreated C4-2B cells ( $\mathrm{P}<0.05$ ). (B) Left panel, association of activated src (p-src), FAK (p-FAK, Tyr 397), paxillin (p-paxillin), Rac (p-Rac), and JNK (p-JNK) in $\alpha 2$ integrin subunit immunoprecipitates. Aliquots of immunoprecipitates were analyzed by direct Western blot analysis, using the respective antibodies. The membranes were reblotted after stripping with anti-FAK, anti-src, anti-paxillin, anti-Rac, and anti-JNK for total FAK, src, paxillin, Rac, and JNK expression and protein loading. Right panel, densitometric band analysis corresponding to phosphorylated src (p-src), FAK (p-FAK, Tyr397), paxillin (p-paxillin), Rac (p-Rac), and JNK (p-JNK) (open bars), vs. total protein levels (closed bars) in the $\alpha 2$ integrin subunit immunoprecipitates (relative intensity). All data are means \pm SD from three independent experiments, asterisks indicate statistical difference from parental LNCaP cells $(\mathrm{P}<0.05)$.

this is the first study demonstrating a role for integrin $\alpha 2$ subunit-mediated signaling leading to activation of MMPs via enhanced activation of the FAK/Src/paxillin/Rac/JNK pathway. Additionally, this study provides new insight into the ability of prostate cancer cells to metastasize to the bone microenvironment since collagen I is abundantly expressed within the bone.

With increasing evidence for cross-talk between several types of membrane receptors and lipids, we suggest that changes in phenotype may be ascribed to the interaction of the different molecules involved with the formation of clusters and association with signaling molecules. Therefore, our results should not be viewed as the action of a single player, but must be seen as a key component that is part of a complex with other membrane proteins and lipids. This idea is supported by recent studies highlighting that cooperation between growth factor receptor and integrin-dependent pathways regulate cancer cell invasion by synergistically inducing FAK and src activation. This has been demonstrated for the c-Met receptor, among others, where its ligand hepatocyte growth factor (HGF)/Scatter factor (SF) stimulates motility on and adhesion, mediated through specific $\beta 1$ integrins, to the ECM (41). The integrin-dependent crosstalk with c-Met receptor and src kinase can be inhibited by expression of the tetraspanin membrane protein KAI1/CD82, which leads to suppressed invasion by reducing the integrin-induced activation of c-Met and activation of src and downstream substrates FAK Tyr861 and p130Cas (42). In contrast, expression of tetraspanin CD151 stimulates integrin-dependent signaling through the FAK-src pathway leading to enhanced motility and protease expression (43). Additionally, the N-terminal domain of FAK mediates the association with growth factor receptors, as epidermal growth factor (EGF), platelet-derived growth factor (PDGF) and c-Met receptors leading to the activation of FAK 
at Tyr397 (32). Moreover, FAK and src also contain binding sites for lipids and may be associated or complexed with glycosphingolipids (GSLs) at the cell surface membrane (44). These GSLs are known to play roles in integrin-mediated cell adhesion, migration and invasion through their effect on signal transduction pathways which is influenced by cross-talk with functional membrane components, including tetraspanins, growth factor receptors and integrins $(6,7,45)$. Further studies along this line are necessary for understanding the complex interplay of the distinct molecules affecting cellular phenotype.

In conclusion, the present study reports a correlation between the spatial organization of integrin $\alpha 2$ subunits and interactions with the extracellular matrix protein collagen I, where cell adhesion and cellular invasion are increased, in the $\mathrm{C} 4-2 \mathrm{~B}$ cell line of the $\mathrm{LNCaP}$ prostate cancer progression model. These observations are concomitant with increased activity of the associated $\mathrm{FAK} / \mathrm{src} /$ paxillin/Rac/JNK signaling pathway leading to activation of matrix metalloproteinases-2 and -9 .

\section{Acknowledgements}

We thank Dr Ingo Janser and Romy Michiels for proofreading this manuscript. This study is supported by the US National Institutes of Health [RR-16480] under the BRIN/INBRE program of the National Center for Research Resources and the New Mexico Tech startup funds and the New Mexico Department of Veteran Services.

\section{References}

1. Christofori G: New signals from the invasive front. Nature 25: 441-450, 2006

2. Vogelstein B and Kinzler KW: Cancer genes and the pathways they control. Nat Med 10: 789-799, 2004.

3. Weber GF: Molecular mechanisms of metastasis. Cancer Lett 270: 181-190, 2007

4. Van Slambrouck S and Steelant WF: Clustering of monosialylGb5 initiates downstream signaling events leading to invasion of MCF-7 breast cancer cells. Biochem J 401: 689-699, 2007.

5. Van slambrouck S, Grijelmo C, De Wever O, Bruyneel E, Emami S, Gespach C and Steelant WF: Activation of the FAKsrc molecular scaffolds and p130Cas-JNK signaling cascades by alpha1-integrins during colon cancer cell invasion. Int J Oncol 231: 1501-1508, 2007

6. Toledo MS, Suzuki E, Handa K and Hakomori S: Effect of ganglioside and tetraspanins in microdomains on interaction of integrins with fibroblast growth factor receptor. J Biol Chem 280: 16227-16234, 2005

7. Todeschini AR, Dos Santos JN, Handa K and Hakomori S: Ganglioside GM2-tetraspanin CD82 complex inhibits met and its cross-talk integrins providing a basis for control of cell motility through glycosynapse. J Biol Chem 282: 8123-8133, 2007.

8. Chatzizacharias NA, Kouraklis GP and Teocharis SE: Clinical significance of FAK expression in human neoplasia. Histol Histopathol 23: 629-650, 2008

9. Mitra SK and Schlaepfer DD: Integrin-regulated FAK-Src signaling in normal and cancer cells. Curr Opin Cell Biol 18: 516-523, 2006

10. Chen SY and Chen HC: Direct interaction of focal adhesion kinase (FAK) with Met is required for FAK to promote hepatocyte growth factor-induced cell invasion. Mol Cell Biol 26: 5155-5167, 2006.

11. Rozengurt E: Mitogenic signaling pathways induced by G protein-coupled receptors. J Cell Physiol 213: 589-602, 2007.

12. Boucheix C, Duc GH, Jasmin C and Rubenstein E: Tetraspanins and malignancy. Expert Rev Mol Med 2001: 1-17, 2001.

13. Schwartz MA: Integrin signaling revisited. Trends Cell Biol 11: 466-470, 2001
14. Schaller MD, Hildebrand JD, Shannon JD, Fox JW, Vines RR and Parsons JT: Autophosphorylation of the focal adhesion kinase, pp125FAK, directs SH2-dependent binding of pp60src. Mol Cell Biol 14: 1680-1688, 1994.

15. Calalb MB, Polte TR and Hanks SK: Tyrosine phosphorylation of focal adhesion kinase at sites in the catalytic domain regulates kinase activity: a role for Src family kinases. Mol Cell Biol 15: 954-963, 1995.

16. Calalb MB, Zhang X, Polte TR and Hanks SK: Focal adhesion kinase tyrosine-861 is a major site of phosphorylation by Src. Biochem Biophys Res Commun 228: 662-668, 1996.

17. Schlaepfer DD and Hunter T: Evidence for in vivo phosphorylation of the Grb2 SH2-domain binding site on focal adhesion kinase by Src-family protein-tyrosine kinases. Mol Cell Biol 16: 5623-5633, 1996

18. Arias-Saldago EG, Lizano S, Sarkar S, Brugge JS, Ginsberg MH and Shattil SJ: Src kinase activation by direct interaction with the integrin beta cytoplasmic domain. Proc Natl Acad Sci USA 100: 13928-13932, 2003.

19. Schlaepfer DD, Jones KC and Hunter T: Multiple Grb2-mediated integrin-stimulated signaling pathways to ERK2/mitogenactivated protein kinase: summation of both src and focal adhesion kinase-initiated tyrosine phosphorylation events. Mol Cell Biol 18: 2571-2585, 1998

20. Petit V, Boyer B, Lentz D, Turner CE, Thiery JP and Valles AM: Phosphorylation of tyrosine residues 31 and 118 on paxillin regulates cell migration through and association with CRK in NBT-II cells. J Cell Biol 6: 957-970, 2006.

21. Valles A, Beuvin M and Boyer B: Activation of Rac1 by Paxillin-Crk-Dock180 Signaling complex is antagonized by Rap1 in migrating NBT-II cells. J Biol Chem 279: 44490-44496, 2004.

22. Hsia DA, Mitra SK, Hauck CR, Strebelow DN, Nelson JA, Ilic D, Huang S, Li E, Nemerow GR, Leng J, Spencer KS, Cheresh DA and Schlaepfer DD: Differential regulation of cell motility and invasion by FAK. J Cell Biol 160: 753-767, 2003.

23. Kurata H, Thant AA, Matsuo S, Senga T, Okazaki K, Hotta N and Hamaguchi M: Constitutive activation of MAP kinase kinase (MEK1) is critical and sufficient for the activation of MMP-2. Exp Cell Res 254: 180-188, 2000

24. Shin M, Yan C and Boyd D: An inhibitor of c-jun aminoterminal kinase (SP600125) represses c-jun activation, DNA binding and PMA-inducible 92-kDa type IV collagenase expression. Biochim Biophys Acta 1589: 311-316, 2000.

25. Brabek J, Constancio SS, Siesser PF, Shin NY, Pozzi A and Hanks SK: Crk-associated substrate tyrosine phosphorylation sites are critical for invasion and metastasis of SRC-transformed cells. Mol Cancer Res 3: 307-315, 2005.

26. Thalmann GN, Sikes RA, Wu TT, Degeorges A, Chang SM Ozen M, Pathak S and Chung LW: LNCaP progression model of human prostate cancer: androgen-independence and osseous metastasis. Prostate 44: 91-103, 2000.

27. Sigstedt SC, Hooten CJ, Callewaert MC, Jenkins AR, Romero AE Pullin MJ, Kornienko A, Lowrey TK, Van slambrouck S and Steelant WF: Evaluation of aqueous extracts of Taraxacum officinale on growth and invasion of breast and prostate cancer cells. Int J Oncol 32: 1085-1090, 2008.

28. Bracke ME, Boterberg T, Bruyneel EA and Mareel MM Collagen Invasion Assay. In: Methods and Molecular Medicine. Brooks SA and Schumacher U (eds). Humana Press, Totowa, New Jersey, pp81-89, 2001.

29. Brown PD, Levy AT, Margulies IM, Liotta LA and StetlerStevenson WG: Independent expression and cellular processing of $\mathrm{Mr} 72,000$ type IV collagenase and interstitial collagenase in human tumorigenic cell lines. Cancer Res 50: 6184-6191, 1990.

30. Björklund $\mathrm{M}$ and Koivunen E: Gelatinase-mediated migration and invasion of cancer cells. Biochim Biophys Acta 1755: 37-69, 2005.

31. Chang YM, Kun HJ and Evans CP: Nonreceptor tyrosine kinases in prostate cancer. Neoplasia 9: 90-100, 2007.

32. Fizazi K: The role of Src in prostate cancer. Ann Oncol 18: 1765-1773, 2007.

33. Davis RJ: Signal transduction by the JNK group of MAP kinases. Cell 103: 239-252, 2000

34. Gullberg D, Gehlsen KR, Turner DC, Ahlén K, Zijenah LS, Barnes MJ and Rubin K: Analysis of alpha 1 beta 1, alpha2 beta 1 and alpha 3 beta 1 integrins in cell-collagen interactions: identification of conformation dependent aplha1 beta 1 binding sites in collagen type I. EMBO J 11: 3863-3873, 1992. 
35. Geho DH, Bandle RW, Clair T and Liotta LA: Physiological mechanisms of tumor-cell invasion and migration. Physiology 20 : 194-200, 2005

36. Chang YM, Bai L, Liu S, Yang JC, Kung HJ and Evans CP: Src family kinase oncogenic potential and pathways in prostate cancer as revealed by AZD0530. Oncogene 27: 6365-6375, 2008.

37. Mariotti A, Kedeshiam PA, Dans M, Curatola AM, Gagnoux-Palaciaos L and Giancotti FG: EGF-R signaling through Fyn kinase disrupts the function of integrin alpha6beta4 at hemidesmosomes: role in epithelial cell migration and carcinoma invasion. J Cell Biol 155: 447-458, 2001.

38. McCall-Culbreath KD and Zutter MM: Collagen receptor integrins: rising to the challenge. Curr Drug Targets 9: 139-149, 2008 .

39. Hall CI, Dai JL, van Golen KL, Keller ET and Long MW: Type I collagen receptor $(\alpha 2 \beta 1)$ signaling promotes the growth of human prostate cancer cells within the bone. Cancer Res 66: 8648-8654, 2008.

40. Sawhney RS, Cookson MM, Omar Y, Hausser J and Brattain MG: Integrin $\alpha 2$-mediated ERK and calpain activation play a critica role in cell adhesion and motility via focal adhesion kinase signaling. J Biol Chem 281: 8497-8510, 2006.
41. Beviglia L and Kramer RH: HGF induces FAK activation and integrin-mediated adhesion in MTLn3 breast carcinoma cells. Int J Cancer 83: 640-649, 1999.

42. Sridhar SC and Miranti CK: Tetraspanin KAI1/CD82 suppresses invasion by inhibiting integrin-dependent crosstalk with c-Met receptor and Src kinases. Oncogene 25: 2367-2378, 2006

43. Hong IK, Jin YJ, Byun HJ, Jeoung DJ, Kim YM and Lee H: Homophilic interactions of Tetraspanin CD151 up-regulate motility and matrix metalloproteinase- 9 expression of human melanoma cells through adhesion-dependent c-Jun activation signaling pathways. J Biol Chem 281: 24279-24292, 2006.

44. Hakomori S: Cell adhesion/recognition and signal transduction through glycosphingolipid microdomain. Glycoconjugate J 17: 143-151, 2000.

45. Hakomori S: Structure and function of glycosphingolipids and sphingolipids: recollections and future trends. Biochim Biophys Acta 1780: 325-346, 2008 